\title{
PROTECTIVE EFFECTS OF MOUTAN CORTEX RADICIS AGAINST ACUTE HEPATOTOXICITY
}

\author{
Juhyun Park, Hyo-Yeon Kim and Sun-Mee Lee ${ }^{*}$ \\ School of Pharmacy, Sungkyunkwan University, Suwon 440-746, Republic of Korea \\ *E-mail: sunmee@skku.edu
}

\begin{abstract}
This study evaluated the potential beneficial effect of Moutan Cortex Radicis (MCR) in a murine model of carbon tetrachloride $\left(\mathrm{CCl}_{4}\right)$-, D-galactosamine $(\mathrm{GalN})$ - and $\alpha$-naphthylisothiocyanate (ANIT)-induced liver injury. Acute hepatotoxicity was induced by intraperitoneal injection of $\mathrm{CCl}_{4}(10 \mu \mathrm{L} / \mathrm{kg})$, GalN $(700 \mathrm{mg} / \mathrm{kg})$, and ANIT $(40 \mathrm{mg} / \mathrm{kg})$. Animals received MCR $\left(30,100\right.$, and $300 \mathrm{mg} / \mathrm{kg}$ ) orally at 48, 24, and $2 \mathrm{~h}$ before and $6 \mathrm{~h}$ after administration of $\mathrm{CCl}_{4}, \mathrm{GalN}$, and ANIT. Serum activities of aminotransferase were significantly higher at $24 \mathrm{~h}$ after $\mathrm{CCl}_{4}$ or GalN treatment. These changes were attenuated by MCR. Histopathological analysis revealed multiple and extensive areas of portal inflammation, hepatocellular necrosis, and an increase in inflammatory cell infiltration. These changes were inhibited by MCR. Serum total bilirubin concentration increased and bile flow decreased significantly $48 \mathrm{~h}$ after ANIT treatment, which was attenuated by MCR. Our results suggest that MCR has a protective effect on acute liver injury.
\end{abstract}

Keywords: carbon tetrachloride, D-galactosamine, inflammation, Moutan Cortex Radicis, $\alpha$-naphthylisothiocyanate

Abbreviations: ALT: alanine aminotransferase; ANIT: $\alpha$-naphthylisothiocyanate; AST: aspartate aminotransferase; $\mathrm{CCl}_{4}$ : carbon tetrachloride; GalN: D-galactosamine; MCR: Moutan Cortex Radicis; TBIL: total bilirubin

\section{Introduction}

Liver diseases constitute a major medical problem of worldwide significance and affect high proportions of the population (Farghali et al., 2009). Many environmental toxins cause liver injury to humans; despite new advances in hepatology, treatment of liver disease does not resolve the problems caused by these toxins. Furthermore, despite considerable progress in treatment of liver disease by oral hepatoprotective agents, the search for newer drugs continues due to the limitations of existing synthetic drugs (Pushpavalli et al., 2009). Therefore, there has been considerable interest in the role of complementary and alternative medicines for treatment of liver diseases.

Carbon tetrachloride $\left(\mathrm{CCl}_{4}\right)$-induced liver injury in a range of laboratory animals is regarded as an analogue of the liver damage caused by various hepatotoxins in humans (Muriel, 1998). Involvement of bioactivation by a microsomal cytochrome P450-dependent monooxygenase system, resulting in formation of trichloromethyl free radicals, leading to hepatocellular damage in hepatic necrosis caused by $\mathrm{CCl}_{4}$ has been suggested (Morio et al., 2001). D-Galactosamine (GalN) is a well-established hepatotoxicant that induces a diffuse type of liver injury closely resembling human viral hepatitis (Aristatile et al., 2009). GalN-induced liver injury reduces the intracellular pool of uracil nucleotides in hepatocytes, thus inhibiting synthesis of RNA and proteins (Siendones et al., 2004). $\alpha$-Naphthylisothiocyanate (ANIT) is a hepatotoxicant that damages biliary cells and hepatocytes; therefore, it is used experimentally in rodents as a model of intrahepatic cholestasis (Xu et al., 2004). ANIT is detoxified by glutathione conjugation within hepatocytes and the complex of ANIT-glutathione is secreted into bile. However, the ANIT-glutathione conjugate dissociates rapidly in bile, leading to release of the parent compound, and exposes biliary epithelial cells to toxic concentrations of ANIT, thus causing hepatobiliary toxicity (Ramaiah and Jaeschke, 2007).

Moutan Cortex Radicis (MCR), the root cortex of Paeonia suffruticosa Andrews (Paeoniaceae), is a well-known traditional herbal medicine used in treatment of cardiovascular and female genital diseases (Hirai et al., 1983; Sakamoto et al., 1992). MCR removes heat from the blood, promotes blood circulation, and removes blood stasis (Chun et al., 2007). MCR has potent analgesic, sedative, anti-inflammatory, and anti-microbial properties (Jiang et al., 2007). Furthermore, MCR has a protective effect on acetaminophen-induced hepatotoxicity in mice (Shon and Nam, 2004). Paeonol, a major phenolic component of MCR, has recently been shown to alleviate alcoholic liver injury via inhibition of hepatic steatosis and inflammation (Hu et al., 2010). GalN, and ANIT.

Therefore, this study examined the hepatoprotective effect of MCR against acute hepatotoxicity induced by $\mathrm{CCl}_{4}$,

\section{Materials and Methods \\ Preparation of an ethanol extract from MCR}

MCR (voucher No. 20100107) was purchased from the Kyung-Dong market (Seoul, Korea) and a dried voucher specimen was authenticated. $500 \mathrm{~g}$ of MCR was extracted in $70 \%$ ethanol at room temperature for $24 \mathrm{~h}$, and three times at 55 
- $60^{\circ} \mathrm{C}$ for $4 \mathrm{~h}$ in 10 times volume of $70 \%$ ethanol. Each extract was filtered through a 150 mesh and concentrated using a rotary evaporator (Model: Cosmos 660, KyungSeo Machine Co., Incheon, Korea). The dry powder of extracts was obtained by freeze-drying and the yield was $18.0 \%$. MCR was dissolved in $10 \%$ Tween 80 (vehicle) for the experiments.

\section{Treatment of animals}

Male ICR mice $(25-30 \mathrm{~g})$ and Sprague-Dawley rats $(190$ - $210 \mathrm{~g})$ were obtained from Daehan Biolink Co., Ltd., (Eumseong, Korea) and acclimatized to the laboratory conditions at Sungkyunkwan University for at least one week. Animals were maintained in a room with controlled temperature and humidity $\left(25 \pm 1^{\circ} \mathrm{C}\right.$ and $55 \pm 5 \%$, respectively) with a $12 \mathrm{~h}$ alternating light-dark cycle. Prior to experimentation, the animals were fasted for $18 \mathrm{~h}$, but given tap water ad libitum. All animals were treated humanely under the Sungkyunkwan University Animal Care Committee Guidelines.

\section{$\mathrm{CCl}_{4}$-induced hepatotoxicity in mice}

$\mathrm{CCl}_{4}$ was dissolved in olive oil and administered intraperitoneally $(10 \mu \mathrm{L} / \mathrm{kg})$. Mice were randomly assigned to five groups: i) vehicle-treated control; ii) vehicle-treated $\mathrm{CCl}_{4}$; iii) MCR 30 (30 mg/kg)-treated CCl 4 ; iv) MCR 100 (100 $\mathrm{mg} / \mathrm{kg}$ )-treated $\left.\mathrm{CCl}_{4} ; \mathrm{v}\right)$ MCR $300(300 \mathrm{mg} / \mathrm{kg})$-treated $\mathrm{CCl}_{4}$. MCR was administered orally at $48 \mathrm{~h}, 24 \mathrm{~h}$, and $2 \mathrm{~h}$ before and $6 \mathrm{~h}$ after $\mathrm{CCl}_{4}$ injection. Dose and timing of MCR were selected based on our preliminary studies. Blood samples were taken from the abdominal aorta and the liver was removed $24 \mathrm{~h}$ after $\mathrm{CCl}_{4}$ treatment.

\section{GalN-induced hepatotoxicity in rats}

GalN was dissolved in phosphate buffered saline (PBS) and administered intraperitoneally $(700 \mathrm{mg} / \mathrm{kg})$. Rats were randomly assigned to five groups: i) vehicle-treated control; ii) vehicle-treated GalN; iii) MCR 30 (30 mg/kg)-treated GalN; iv) MCR $100(100 \mathrm{mg} / \mathrm{kg})$-treated GalN; v) MCR $300(300 \mathrm{mg} / \mathrm{kg})$-treated GalN. MCR was administered orally at $48 \mathrm{~h}, 24 \mathrm{~h}$, and $2 \mathrm{~h}$ before and $6 \mathrm{~h}$ after GalN injection. Blood samples were taken from the abdominal aorta and the liver was removed $24 \mathrm{~h}$ after GalN treatment.

\section{ANIT-induced hepatotoxicity in rats}

ANIT was dissolved in olive oil and injected intraperitoneally $(40 \mathrm{mg} / \mathrm{kg})$. Rats were randomly assigned to five groups: i) vehicle-treated control; ii) vehicle-treated ANIT; iii) MCR 30 (30 mg/kg)-treated ANIT; iv) MCR 100 (100 $\mathrm{mg} / \mathrm{kg}$ )-treated ANIT; v) MCR $300(300 \mathrm{mg} / \mathrm{kg})$-treated ANIT. MCR was administered orally $48 \mathrm{~h}, 24 \mathrm{~h}$, and $2 \mathrm{~h}$ before and 6 $\mathrm{h}$ after ANIT injection. Blood samples were taken from the abdominal aorta and the liver was removed $48 \mathrm{~h}$ after ANIT treatment.

\section{Serum aminotransferase activities and total bilirubin concentration}

Levels of serum alanine aminotransferase (ALT) and aspartate aminotransferase (AST) activity and total bilirubin (TBIL) concentration were determined by standard spectrophotometric procedures using the ChemiLab ALT, AST, and TBIL assay kits (IVDLab Co., Ltd., Uiwang, Korea), respectively.

\section{Histological analysis}

The anterior portion of the left lateral lobe of the liver was sectioned and used for histological analysis. Tissues were fixed by immersion in $10 \%$ neutral-buffered formalin. Samples were then embedded in paraffin, sliced into $5 \mu \mathrm{m}$ sections, stained with hematoxylin-eosin, followed by blinded histological assessment. The degree of portal inflammation, hepatocellular necrosis, and inflammatory cell infiltration was evaluated (Frei et al., 1984). Histological changes were evaluated in non-consecutive, randomly chosen x 400 histological fields.

\section{Bile flow}

At $48 \mathrm{~h}$ after ANIT treatment, rats were anesthetized intraperitoneally with ketamine $(60 \mathrm{mg} / \mathrm{kg}$ body weight $)$ and xylazine $(10 \mathrm{mg} / \mathrm{kg}$ body weight) and placed on a heating pad in order to maintain body temperature. A midline incision was made in the rat, and the common bile duct was isolated and cannulated with PE 10 tubing. Bile was collected for a 60 min period. Bile and liver samples were weighed, and bile flow was calculated, assuming a density of $1 \mathrm{~g} / \mathrm{mL}$.

\section{Statistical analysis}

The overall significance of the results was examined using one-way analysis of variance (ANOVA). Differences between the groups were considered statistically significant at $P<0.05$ with the appropriate Bonferroni correction made for multiple comparisons. Results are presented as mean \pm S.E.M.

\section{Results and Discussion}

In this study, the protective effect of MCR was examined using a model of $\mathrm{CCl}_{4^{-}}$, GalN, and ANIT-induced 
hepatotoxicity. $\mathrm{CCl}_{4}$, a classic hepatotoxin, caused acute, reversible liver injury characterized by centrilobular necrosis (Son et al., 2007). Hepatotoxicity of $\mathrm{CCl}_{4}$ is thought to involve two phases. The first phase consists of activation by cytochrome P450 2E1, 2B1, or 2B2 in the liver to form a highly reactive trichloromethyl radical and then a trichloromethyl peroxy radical (Yamaji et al., 2008). These radicals can attack membrane phospholipid stimulating lipid peroxidation and cell lysis. This damage to the structural integrity of the liver was observed from elevated serum levels of hepatospecific enzymes, i.e. AST and ALT (Aktay et al., 2000). The second phase is caused by the inflammatory response, which involves activation of Kupffer cells, probably by free radicals. Activation of Kupffer cells is accompanied by production of proinflammatory mediators (Chen et al., 2004).

As shown in Table 1, serum ALT activity in the control group averaged $25.5 \pm 1.2 \mathrm{U} / \mathrm{L}$. However, the value in the vehicle-treated $\mathrm{CCl}_{4}$ group showed a dramatic increase $(1983.0 \pm 28.6 \mathrm{U} / \mathrm{L}, P<0.01)$, indicating severe hepatocellular damage. Treatment with MCR, at doses of 30,100 , and $300 \mathrm{mg} / \mathrm{kg}$ resulted in a markedly attenuated increase in ALT activity to approximately $66.3 \%, 54.3 \%$, and $37.3 \%$ of that in the vehicle-treated $\mathrm{CCl}_{4}$ group, respectively. Consistent with the ALT data, the serum level of AST increased significantly from $46.4 \pm 6.7 \mathrm{U} / \mathrm{L}$ to $1764.0 \pm 158.1 \mathrm{U} / \mathrm{L}$, and this increase was reduced by 30,100 , and $300 \mathrm{mg} / \mathrm{kg}$ of MCR. Histological observation of liver samples strongly supported the release of aminotransferases by damaged hepatocytes, as well as the protective effect of MCR. The histological features shown in Figure 1A demonstrated normal liver lobular architecture and cell structure in the control group. In contrast, the vehicletreated $\mathrm{CCl}_{4}$ group exhibited various histological changes to the liver, including cell necrosis, fatty metamorphosis in adjacent hepatocytes, ballooning degeneration, cell inflammation, and infiltration of lymphocytes and Kupffer cells (Figure 1B). These alterations were significantly attenuated by $300 \mathrm{mg} / \mathrm{kg}$ of MCR, showing mild hepatocellular necrosis and inflammation (Figure 1C). These results suggest that MCR may have potential clinical applications for treatment of liver disorders.

In terms of both morphological and functional aspects, GalN-induced acute injury in rat livers is well-established and recognized as resembling viral hepatitis in humans (Decker and Keppler, 1972). The toxic effect of GalN is connected with an insufficiency of UDP-glucose and UDP-galactose, as well as loss of intracellular calcium homeostasis. These changes affect cell membranes and organelles, as well as synthesis of proteins and nucleic acids (Devaki et al., 2009). Recent studies have demonstrated that GalN can induce hepatic hypoxia/hypoperfusion and trigger production of reactive oxygen species from affected hepatocytes, infiltrated leukocytes, and activated Kupffer cells and enhance mitochondrial apoptosisand the proinflammatory cytokine-signaling pathway, contributing to oxidative stress and inflammation in the liver (Lin et al., 2009).

Table 1: Effect of MCR on serum aminotransferase activities in mice after $\mathrm{CCl}_{4}$ administration

\begin{tabular}{|c|c|c|c|c|}
\hline & & Dose (mg/kg) & ALT (U/L) & AST (U/L) \\
\hline $\begin{array}{l}\text { Control } \\
\mathrm{CCl}_{4}\end{array}$ & & & $25.5 \pm 1.2$ & $46.4 \pm 6.7$ \\
\hline & Vehicle & & $1983.0 \pm 28.6^{* *}$ & $1764.0 \pm 158.1^{* *}$ \\
\hline & MCR & 30 & $1316.0 \pm 196.2^{* *}$ & $1181.0 \pm 128.0^{* *}$ \\
\hline & & 100 & $1076.0 \pm 120.1^{* *}, \#$ & $1239.0 \pm 94.5^{* *}$ \\
\hline & & 300 & $739.4 \pm 174.2^{* *}$ & $960.3 \pm 86.7^{* *}, \# \#$ \\
\hline
\end{tabular}

The results are presented as mean \pm S.E.M. of 8-10 mice per group. ${ }^{* *}$ Denotes significant differences $(P<0.01)$ compared with the control group; ${ }^{\#}$, denote significant differences $(P<0.05, P<0.01)$ compared with the vehicle-treated $\mathrm{CCl}_{4}$ group. $^{\circ}$ ALT: alanine aminotransferase; AST: aspartate aminotransferase; MCR: Moutan Cortex Radicis.

Table 2: Effect of MCR on serum aminotransferase activities in rats after GalN administration

\begin{tabular}{|c|c|c|c|c|}
\hline \multirow{7}{*}{$\begin{array}{l}\text { Group } \\
\text { Control } \\
\text { GalN }\end{array}$} & & Dose $(\mathrm{mg} / \mathrm{kg})$ & ALT (U/L) & $\mathrm{AST}(\mathrm{U} / \mathrm{L})$ \\
\hline & & & $44.4 \pm 1.0$ & $81.5 \pm 0.8$ \\
\hline & & & & \\
\hline & Vehicle & & $235.7 \pm 28.6^{* *}$ & $664.6 \pm 41.7^{* *}$ \\
\hline & MCR & 30 & $168.8 \pm 9.2^{* *}, \#$ & $539.4 \pm 27.5^{* *} \#$ \\
\hline & & 100 & $155.9 \pm 13.3^{* *, \#}$ & $468.8 \pm 18.8^{* *}$ \\
\hline & & 300 & $148.3 \pm 19.2^{* *, \#}$ & $530.1 \pm 28.3^{* *} \#$ \\
\hline
\end{tabular}

The results are presented as mean \pm S.E.M. of $8-10$ rats per group. ${ }^{* *}$ Denotes significant differences $(P<0.01)$ compared

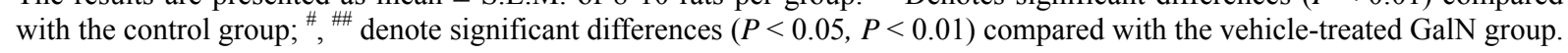
ALT: alanine aminotransferase; AST: aspartate aminotransferase; MCR: Moutan Cortex Radicis. 

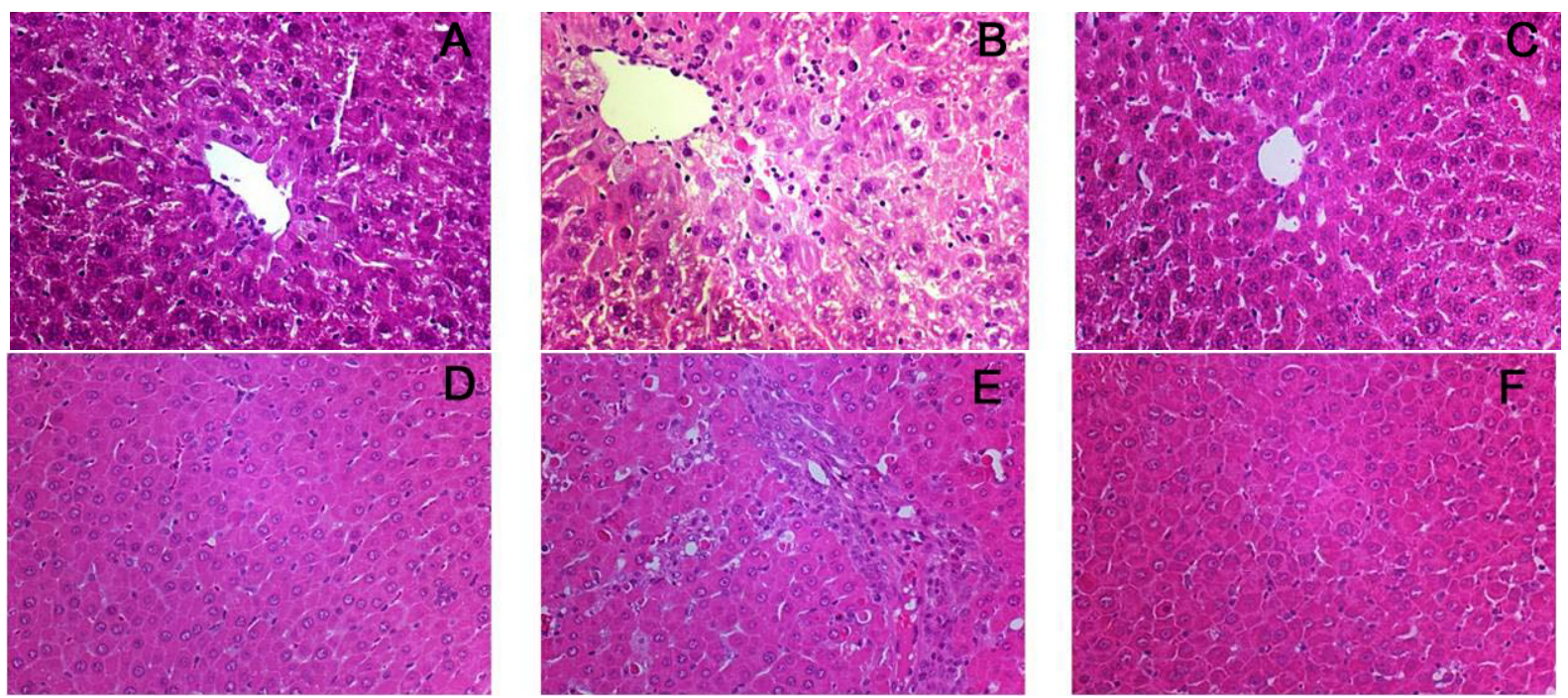

Figure 1: Histological features of liver sections stained with hematoxylin and eosin at $24 \mathrm{~h}$ after $\mathrm{CCl}_{4}(\mathrm{~A}-\mathrm{C})$ or GalN (D-F) exposure. Typical images were chosen from each experimental group (original magnification $\times 400$ ). (A): The control group, showing normal lobular architecture and cell structure; (B): The vehicle-treated $\mathrm{CCl}_{4}$ group, showing multiple and extensive areas of portal inflammation and hepatocellular necrosis, and a moderate increase in inflammatory cell infiltration; $(\mathrm{C})$ : $\mathrm{CCl}_{4}$ + MCR (300 mg/kg) group, showing minimal hepatocellular necrosis and inflammatory cell infiltration, and mild portal inflammation; (D): The control group, showing normal hepatic architecture; (E): The vehicle-treated GalN group, showing hepatocellular necrosis with extensive inflammation and inflammatory cell infiltration; (F): GalN + MCR (300 mg/kg) group, showing mild hepatocellular necrosis and inflammatory infiltration.

In the present study, serum ALT activity in the control group was $44.4 \pm 1.0 \mathrm{U} / \mathrm{L}$. The vehicle-treated GalN group showed a significant increase in serum ALT activity at $24 \mathrm{~h}$ after GalN injection $(235.7 \pm 28.6 \mathrm{U} / \mathrm{L}, P<0.01)$. In contrast, treatment with MCR at doses of 30,100, and $300 \mathrm{mg} / \mathrm{kg}$ attenuated the increase in ALT activity to approximately $71.6 \%$, $66.1 \%$, and $62.9 \%$ of that in the vehicle-treated GalN group, respectively. The serum level of AST also showed a significant increase from $81.5 \pm 0.8 \mathrm{U} / \mathrm{L}$ to $664.6 \pm 41.7 \mathrm{U} / \mathrm{L}$, and this increase was reduced by 30,100 , and $300 \mathrm{mg} / \mathrm{kg}$ of MCR (Table 2). The histological features shown in Figure 1D demonstrate normal liver lobular architecture and cell structure in the control group. However, livers exposed to GalN showed multiple and extensive areas of portal inflammation and hepatocellular necrosis, randomly distributed throughout the parenchyma, as well as a moderate increase in inflammatory cell infiltration (Figure 1E). These pathological changes were attenuated by $300 \mathrm{mg} / \mathrm{kg}$ of MCR (Figure 1F). Taken together, our results suggest that MCR has a potential for use as a therapeutic agent for treatment of acute hepatitis.

The key function of the liver is to synthesize, concentrate, and secrete bile acids and to excrete other toxicants, such as bilirubin. ANIT induces bile duct epithelial cell necrosis, followed by cessation of bile flow, and consequent hyperbilirubinemia (Hasegawa et al., 2008). Due to its dose-dependent effects and high reproducibility between studies, ANIT is a typical hepatotoxin used in the study of intrahepatic cholestasis (Hasegawa et al., 2008). This drug provokes an acute cholestatic hepatitis, due in part to its recycling through repeated rounds of glutathione conjugation and biliary excretion (Kodali et al., 2006). The drug is initially detoxified in hepatocytes by conjugation with glutathione (Xu et al., 2004). Instability of the ANIT-glutathione conjugate and recycling rounds of ANIT metabolism result in high ANIT concentration in bile (Luyendyk et al., 2009). This causes bile duct epithelial cell damage and formation of foci of hepatic necrosis characterized by dead hepatocytes (Luyendyk et al., 2009).

According to our results, serum TBIL concentration was $0.077 \pm 0.027 \mathrm{mg} / \mathrm{dL}$ in the control group. However, the vehicle-treated ANIT group showed significantly increased serum TBIL concentration by approximately 8.6 times that of the control group. Treatment with MCR at doses of 100 and $300 \mathrm{mg} / \mathrm{kg}$ attenuated an increase in TBIL concentration to approximately $62.5 \%$ and $36.1 \%$ of that in the vehicle-treated ANIT group, respectively (Figure $2 \mathrm{~A}$ ). Bile flow in the control group was $2.249 \pm 0.252 \mathrm{~mL} / \mathrm{min} / \mathrm{g}$ liver. In the vehicle-treated ANIT group, bile flow showed a significant decrease $(0.379 \pm$ $0.023 \mathrm{~mL} / \mathrm{min} / \mathrm{g}$ liver, $P<0.01)$; however, treatment with MCR, at doses of 30,100 and $300 \mathrm{mg} / \mathrm{kg}$ attenuated this decrease in bile flow (Figure 2B). These results indicate that MCR may offer protection to hepatocytes and bile duct epithelial cells against acute liver cholestasis.

\section{Conclusion}

MCR may prevent $\mathrm{CCl}_{4^{-}}, \mathrm{GalN}-$, and ANIT-induced acute hepatic injury. This study provides evidence of the potential of MCR as an alternative treatment for liver diseases. Further studies will be needed in order to achieve a full understanding of the underlying mechanism in the hepatoprotective effect of MCR against acute hepatotoxicity. 
A

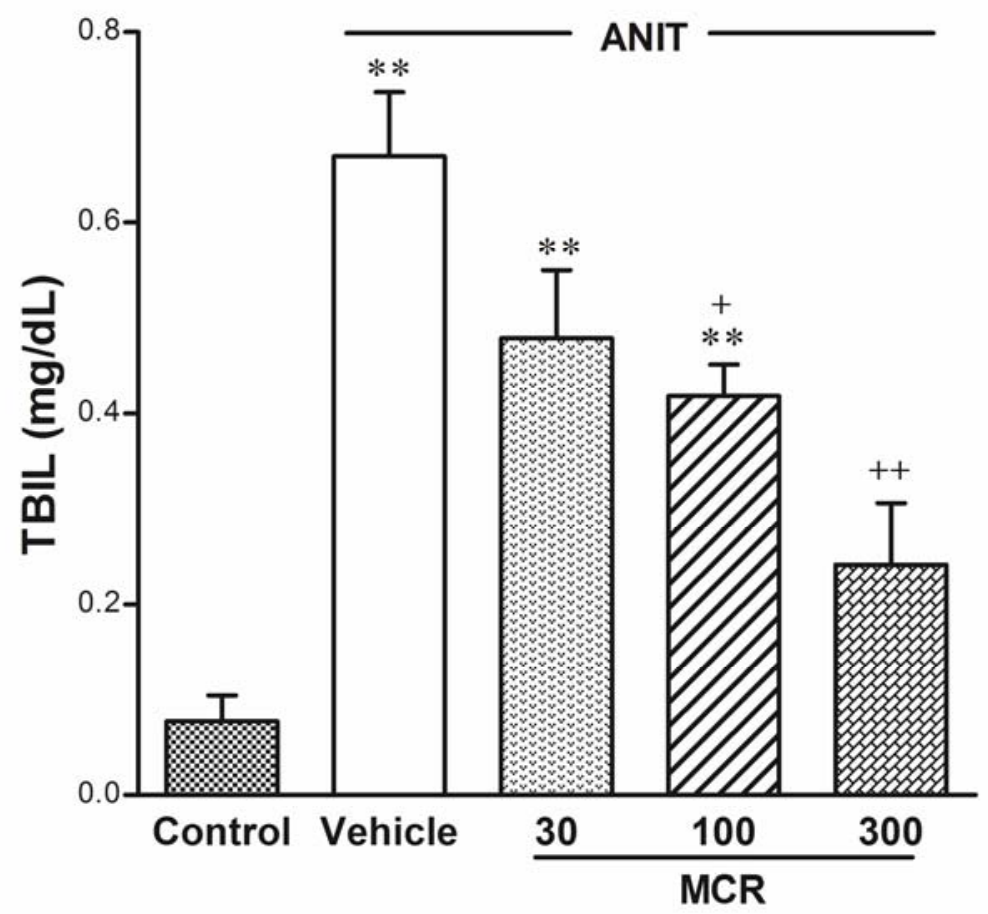

B

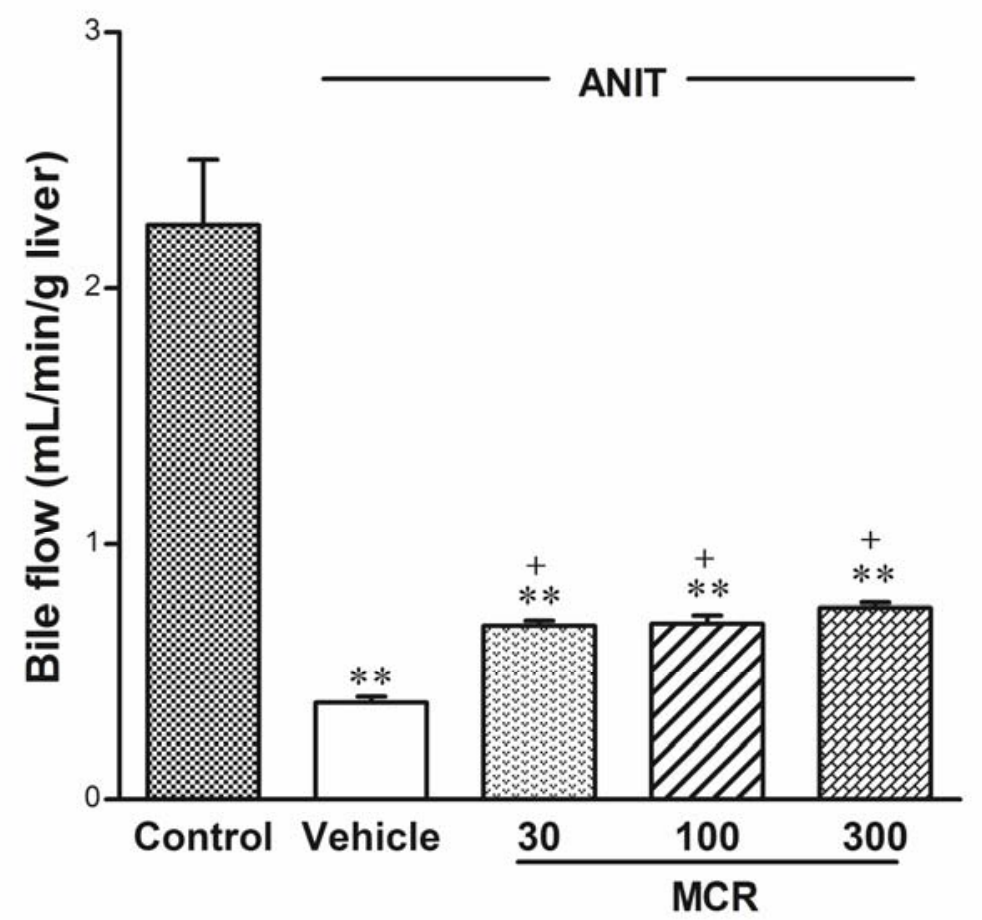

Figure 2: Effect of MCR on serum total bilirubin (A) and bile flow (B) in ANIT-induced acute hepatotoxicity. The values are represented as mean \pm S.E.M. for 8 -10 rats per group. ${ }^{* *}$ Denotes significant differences $(P<0.01)$ compared with the control group; ${ }^{+},{ }^{+}$denote significant differences $(P<0.05, P<0.01)$ compared with the vehicle-treated ANIT group. ANIT: $\alpha-$ naphthylisothiocyanate; TBIL: total bilirubin; MCR: Moutan Cortex Radicis.

\section{Acknowledgments}

This work is financially supported by the Ministry of Education, Science and Technology (MEST), the Ministry of 
Knowledge Economy (MKE) through the fostering project of HUNIC.

\section{References}

1. Aktay, G., Deliorman, D., Ergun, E., Ergun, F., Yesilada, E. and Cevik, C. (2000). Hepatoprotective effects of Turkish folk remedies on experimental liver injury. J. Ethnopharmacol., 73: 121-129.

2. Aristatile, B., Al-Numair, K. S., Veeramani, C. and Pugalendi, K. V. (2009). Effect of carvacrol on hepatic marker enzymes and antioxidant status in D-galactosamine-induced hepatotoxicity in rats. Fundam. Clin. Pharmacol., 23: 757-765.

3. $\quad$ Chen, J. H., Tipoe, G. L., Liong, E. C., So, H. S., Leung, K. M., Tom, W. M., Fung, P. C. and Nanji, A. A. (2004). Green tea polyphenols prevent toxin-induced hepatotoxicity in mice by down-regulating inducible nitric oxide-derived prooxidants. Am. J. Clin. Nutr., 80: 742-751.

4. $\quad$ Chun, S. C., Jee, S. Y., Lee, S. G., Park, S. J., Lee, J. R. and Kim, S. C. (2007). Anti-Inflammatory Activity of the Methanol Extract of Moutan Cortex in LPS-Activated Raw264.7 Cells. Evid. Based. Complement. Alternat. Med., 4: $327-$ 333.

5. $\quad$ Decker, K. and Keppler, D. (1972). Galactosamine induced liver injury. Prog. Liver Dis., 4: 183-199.

6. Devaki, T., Sathivel, A. and BalajiRaghavendran, H. R. (2009). Stabilization of mitochondrial and microsomal function by polysaccharide of Ulva lactuca on D-Galactosamine induced hepatitis in rats. Chem. Biol. Interact., 177: 83-88.

7. $\quad$ Farghali, H., Cerny, D., Kamenikova, L., Martinek, J., Horinek, A., Kmonickova, E. and Zidek, Z. (2009). Resveratrol attenuates lipopolysaccharide-induced hepatitis in D-galactosamine sensitized rats: role of nitric oxide synthase 2 and heme oxygenase-1. Nitric Oxide, 21: 216-225.

8. Frei, A., Zimmermann, A. and Weigand, K. (1984). The N-terminal propeptide of collagen type III in serum reflects activity and degree of fibrosis in patients with chronic liver disease. Hepatology, 4: 830-834.

9. Hasegawa, M., Ide, M., Fujita, T. and Takenaka, S. (2008). Urinary metabolic fingerprinting for alphanaphthylisothiocyanate-induced intrahepatic cholestasis in rats using Fourier transform-ion cyclotron resonance mass spectrometry. Toxicol. Pathol., 36: 818-826.

10. Hirai, A., Terano, T., Hamazaki, T., Sajiki, J., Saito, H., Tahara, K., Tamura, Y. and Kumagai, A. (1983). Studies on the mechanism of antiaggregatory effect of Moutan Cortex. Thromb. Res., 31: 29-40.

11. Hu, S., Shen, G., Zhao, W., Wang, F., Jiang, X. and Huang, D. (2010). Paeonol, the main active principles of Paeonia moutan, ameliorates alcoholic steatohepatitis in mice. J. Ethnopharmacol., 128: 100-106.

12. Jiang, S., Nakano, Y., Yatsuzuka, R., Ono, R. and Kamei, C. (2007). Inhibitory effects of Moutan cortex on immediate allergic reactions. Biol. Pharm. Bull., 30: 1707-1710.

13. Kodali, P., Wu, P., Lahiji, P. A., Brown, E. J. and Maher, J. J. (2006). ANIT toxicity toward mouse hepatocytes in vivo is mediated primarily by neutrophils via CD18. Am. J. Physiol., 291: G355-G363.

14. Lin, B. R., Yu, C. J., Chen, W. C., Lee, H. S., Chang, H. M., Lee, Y. C., Chien, C. T. and Chen, C. F. (2009). Green tea extract supplement reduces D-galactosamine-induced acute liver injury by inhibition of apoptotic and proinflammatory signaling. J. Biomed. Sci., 16: 35.

15. Luyendyk, J. P., Cantor, G. H., Kirchhofer, D., Mackman, N., Copple, B. L. and Wang, R. (2009). Tissue factordependent coagulation contributes to alpha-naphthylisothiocyanate-induced cholestatic liver injury in mice. Am. J. Physiol., 296: G840-G849.

16. Morio, L. A., Chiu, H., Sprowles, K. A., Zhou, P., Heck, D. E., Gordon, M. K. and Laskin, D. L. (2001). Distinct roles of tumor necrosis factor-alpha and nitric oxide in acute liver injury induced by carbon tetrachloride in mice. Toxicol. Appl. Pharmacol., 172: 44-51.

17. Muriel, P. (1998). Nitric oxide protection of rat liver from lipid peroxidation, collagen accumulation, and liver damage induced by carbon tetrachloride. Biochem. Pharmacol., 56: 773-779.

18. Pushpavalli, G., Veeramani, C. and Pugalendi, K. V. (2009). Effect of Piper betle on plasma antioxidant status and lipid profile against D-galactosamine-induced hepatitis in rats. Redox. Rep., 14: 7-12.

19. Ramaiah, S. K. and Jaeschke, H. (2007). Role of neutrophils in the pathogenesis of acute inflammatory liver injury. Toxicol. Pathol., 35: 757-766.

20. Sakamoto, S., Yoshino, H., Shirahata, Y., Shimodairo, K. and Okamoto, R. (1992). Pharmacotherapeutic effects of kuei-chih-fu-ling-wan (keishi-bukuryo-gan) on human uterine myomas. Am. J. Chin. Med., 20: 313-317.

21. Shon, Y. H. and Nam, K. S. (2004). Protective effect of Moutan Cortex extract on acetaminophen-induced hepatotoxicity in mice. J. Ethnopharmacol., 90: 415-419.

22. Siendones, E., Fouad, D., Diaz-Guerra, M. J., de la Mata, M., Bosca, L. and Muntane, J. (2004). PGE1-induced NO reduces apoptosis by D-galactosamine through attenuation of NF-kappaB and NOS-2 expression in rat hepatocytes. Hepatology, 40: 1295-1303.

23. Son, G., Iimuro, Y., Seki, E., Hirano, T., Kaneda, Y. and Fujimoto, J. (2007). Selective inactivation of NF-kappaB in the liver using NF-kappaB decoy suppresses $\mathrm{CCl}_{4}$-induced liver injury and fibrosis. Am. J. Physiol., 293: G631-G639.

24. Xu, J., Lee, G., Wang, H., Vierling, J. M. and Maher, J. J. (2004). Limited role for CXC chemokines in the pathogenesis of alpha-naphthylisothiocyanate-induced liver injury. Am. J. Physiol., 287: G734-G741.

25. Yamaji, K., Ohnishi, K., Zuinen, R., Ochiai, Y., Chikuma, T. and Hojo, H. (2008). Interleukin-6 production by peritoneal mesothelial cells and its regulation by inflammatory factors in rats administered carbon tetrachloride intraperitoneally. Toxicol. Appl. Pharmacol., 226: 38-45. 